Article

\title{
Optimal Power Dispatch of an Offshore Wind Farm under Generator Fault
}

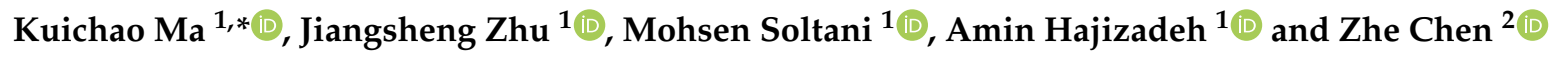 \\ 1 Department of Energy Technology, Aalborg University, 6700 Esbjerg, Denmark; jzh@et.aau.dk (J.Z.); \\ sms@et.aau.dk (M.S.); aha@et.aau.dk (A.H.) \\ 2 Department of Energy Technology, Aalborg University, 9220 Aalborg, Denmark; zch@et.aau.dk \\ * Correspondence: kum@et.aau.dk; Tel.: +45-9356-2139
}

Received: 29 January 2019; Accepted: 15 March 2019; Published: 20 March 2019

\begin{abstract}
For offshore wind farms, the power loss caused by the wake effect is large due to the large capacity of the wind turbine. At the same time, the operating environment of the offshore wind farm is very harsh, and the cost of maintenance is higher than that of the onshore wind farm. Therefore, it is worthwhile to study through reasonable control how to reduce the wake loss of the wind farm and minimize the losses caused by the fault. In this paper, the Particle Swarm Optimization (PSO) algorithm is used to optimize the active power dispatch of wind farms under generator cooling system faults. The optimization objectives include avoiding the further deterioration of the generator fault, reducing unnecessary power loss of the faulty wind turbine, tracking the power demand from the Transmission System Operator (TSO), and reducing the power fluctuation caused by the PSO algorithm. The proposed optimal power dispatch strategy was compared with the two generally-used fault-handling methods and the proportional dispatch strategy in simulation. The result shows that the proposed strategy can improve the power generation capacity of the wind farm and achieve an efficient trade-off between power generation and fault protection.
\end{abstract}

Keywords: wind energy; power dispatch; offshore wind farm; particle swarm optimization; fault accommodation

\section{Introduction}

With the recent rapid development of wind energy, the form of wind energy has gradually developed from distributed onshore to centralized offshore. Most Wind Farms (WFs) are directly connected to the grid. Therefore, for the grid, it is more desirable to treat WFs like conventional power plants. In other words, the ideal WF should operate as a conventional power plant [1]. In addition to the uncontrollable and variable wind resources, WFs have many different characteristics compared to conventional power plants as follows:

- The operating environment of a WF is very harsh. That will increase the failure rate of the components of a Wind Turbine (WT). Therefore, more attention should be paid to the influence of the fault and failure of WTs on WFs.

- WFs usually consist of dozens of independent WTs. WF operators need to coordinate and manage all the WTs to meet the requirements from the grid.

- There is an aerodynamic interaction among the WTs. The wake effect can cause $30-50 \%$ power loss of WFs and increase the fatigue loads of the downstream WTs [2]. The optimal operation of individual WTs cannot result in the optimal operation of the whole WF with respect to power production or loads. 
From the characteristics of WFs described above, it can be seen that the Wind Farm Control (WFC) considering faults is very necessary to optimize the WF performance and accommodate the unexpected faults, especially for offshore WFs. The wind resources at sea are abundant, and the capacity of the WT is usually large. Unplanned maintenance caused by faults will result in large power losses. Moreover, offshore WTs have high maintenance costs, and the maintenance is affected by many weather factors, such as wind speed and wave height. Therefore, if there is an effective WFC, under the premise of ensuring the safety of the WT, it can not only protect the faulty WT, but also track the power demand from the Transmission System Operator (TSO) as much as possible. It will be able to reduce the power losses caused by the faulty turbine, as well as lower the maintenance costs.

Active Power Regulation (APR) of WFs as a part of WFC has been an important topic of research in recent years. The wake effect is one of the causes of WF power loss. Many researchers have focused on how to reduce the wake effect to improve the power generation [3-5]. This concept was named Active Wake Control (AWC) in [6]. Two different methods are commonly used. One method is axial induction control, which is more widely used [4,5]. In general, axial induction control achieves the control objectives by adjusting the Tip Speed Ratio (TSR) and the pitch angle of the WT blades. It is not as effective at improving power as other methods. The implementation of axial induction control requires access to the original control system of the WT. This will pose a threat to the safety of the WT. Therefore, the axial induction control can only be adopted by the manufacturer. Otherwise, the potential voiding of the warranty of the WT will be an unavoidable problem. The other method is yaw-based AWC. In this method, the upstream WT is operated with rotor yaw misalignment to divert the wake away from the downstream WT [7]. This method is very effective for improving the power of the WF. However, the weakness of this method is that it will increase the fatigue loads of the individual WTs [8]. Moreover, in practice, due to the slow response speed of the yaw control, the WT may not be able to track the yaw angle reference in time. In addition to these two methods, the easiest way to implement WFC is power dispatch, which optimizes the WF power by adjusting the power reference of the individual WTs. It is more of a WF management than a WFC one. This method does not affect the WTs' original control system. Although this method cannot increase the WF power as much as the former methods, it is highly feasible and more suitable for practical application. Therefore, this paper adopted the power dispatch method to optimize the power of the WF in the fault condition.

Another focus of this paper is WT fault. Many studies focused on the fault detection and prediction for various common faults, such as generator faults, gearbox faults, and blade damage $[9,10]$. The fault characteristics are obtained by analyzing some physical signals of the system or using an additional detection device. Condition monitoring and fault diagnosis are the first steps in implementing fault accommodation. When a fault is detected or predicted, WTC and WFC can perform corresponding pre-set actions. Some studies used fault analysis methods such as Fault Tree Analysis (FTA) and Failure Mode and Effects Analysis (FMEA) to analyze the fault cause, process, and effect [11,12]. These analysis results can be used to help the WTC and WFC design for fault accommodation. A test benchmark model for the fault detection and accommodation was proposed in [13]. The authors aimed at reducing the impact of the WT fault on the WF at the WF level, but focused on the blade erosion and debris build-up on the blades in [14]. The generator, which converts mechanical energy into electrical energy, is one of the most important components of the WT. Figure 1 shows the normalized failure rates and downtimes for main components in MW-class WTs [15]. It can be seen that, although the failure rate of the generator is not the highest, the downtime is quite long. Many generator faults are related to overheating, such as stator winding insulation faults. In general, at the beginning of the fault, it is just an inter-turn short circuit in a single-phase winding. However, as the fault progresses, the faulty phase current increases, which will lead to further damage of the insulation, and finally to a phase-to-phase short circuit or phase-to-ground short circuit. As a rule of thumb, the insulation lifetime is reduced by half for each $10{ }^{\circ} \mathrm{C}$ that the motor temperature exceeds its rated insulation temperature [16]. In addition, when the temperature of a generator exceeds a specific value, the WT will automatically shut down to protect the windings [17]. Therefore, the cooling system for generator 
windings is very important. When a cooling system fault occurs, the cooling capacity will be decreased. Long-term operation at high temperatures will lead to the aging of the windings' insulation. To avoid the damage of insulation under a cooling system fault, the phase current of the generator has to be reduced. That means the power of the faulty generator should be limited to reduce the heat generation and protect the generator. Because of this, fault protection and down-regulation can be linked. In the process of power dispatch, the power reference of a faulty turbine will be limited to a specific power value based on the severity of the fault.

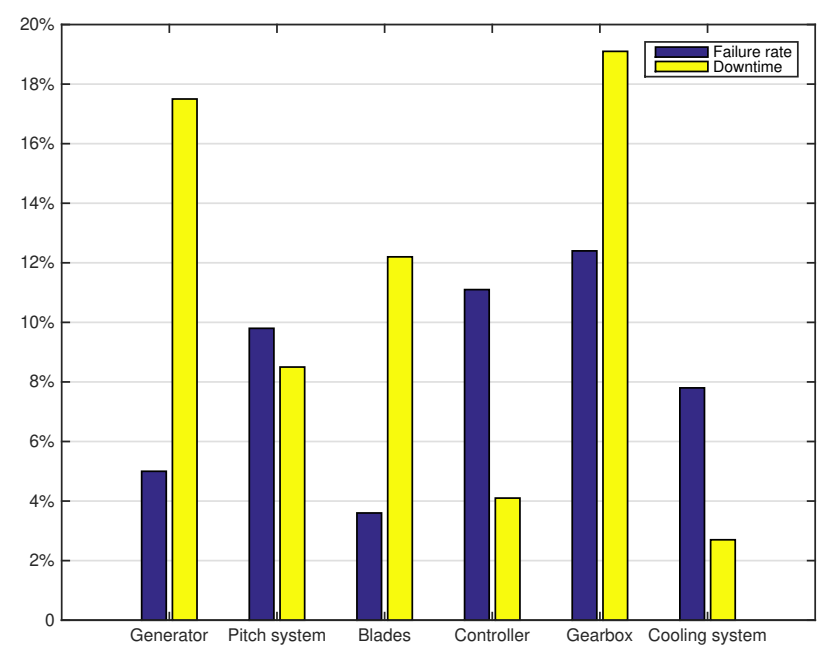

Figure 1. Normalized failure rates and downtimes of a wind turbine.

The contribution of this paper is to consider generator cooling system faults in the WF dispatch strategy. First, the safe operating power of the faulty WT is calculated based on the thermal model of the generator. Then, the safe operating power is taken as the power limit of this faulty WT. This will prevent the generator from operating under overheating conditions. According to [16], the insulation life of the generator windings will be reasonably protected. Considering the wake effect, this paper optimizes the multi-objectives through Particle Swarm Optimization (PSO): power tracking, power fluctuation and fault protection. Compared with the way that the WF usually handles the faulty WT, this method not only avoids the fault deterioration caused by the unreasonable operation in the fault state, but also reduces the power loss caused by direct shutdown. Compared with the Proportional Dispatch Strategy (PDS) that does not take the wake effect into account, the proposed strategy can better track the power demand from the TSO under the premise of protecting the faulty WT and obtain an efficient trade-off between fault protection and power tracking.

The structure of this paper is as follows: the WF model, consisting of the WT model, WF layout, and wake effect model, is presented in Section 2; the fault model of the generator cooling system is presented in Section 3; the optimal power dispatch strategy with fault accommodation is presented in Section 4; the simulation results and analysis are in Section 5; finally, conclusions are given in Section 6.

\section{Wind Farm Model}

Since the content of this paper is the active power dispatch optimization of WFs and the dynamic process of WTs is not involved in the design, the static model is enough to illustrate the effect of the proposed strategy. The WF model consists of three parts. The first part is the WT model, which is used to describe the aerodynamic and power generation characteristics of the WT. The second part is the WF layout, which is also an important attribute of the WF. The arrangement of the WTs affects the aerodynamic interaction in the WF directly. The last part is the wake model, which is used to describe the aerodynamic interaction among the WTs. Here, the Jensen wake model, which is widely used in engineering, is adopted. 


\subsection{Wind Turbine Model}

The WT model used here is a static model, which is based on the modified NREL 5-MW turbine model in SimWindFarm Simulink toolbox [18], as shown in Figure 2. The input of the model is power reference, $P_{\mathrm{r}}$, and wind speed, $v$. The WTC adopted the region control [19] in the non-down-regulation condition and the maximum $\omega$ strategy [20] in the down-regulation condition. According to the WTC, when the wind speed and power reference are determined, the references of pitch angle, $\beta$, and TSR, $\lambda$, can be obtained. Then, $\beta$ and $\lambda$ will determine the specific power coefficient, $C_{p}$, and thrust coefficient, $C_{\mathrm{t}}$. Both $C_{\mathrm{p}}$ and $C_{\mathrm{t}}$ are functions of $\beta$ and $\lambda$. They are derived from the $C_{\mathrm{p}}$ and $C_{\mathrm{t}}$ surfaces. The output of the WT model is the power output and $C_{\mathrm{t}}$. The power output can be expressed as:

$$
P=\frac{1}{2} \rho \pi R^{2} v^{3} C_{\mathrm{p}} \eta
$$

where $\rho$ is the air density, $R$ is the radius of the turbine rotor, and $\eta$ is the conversion efficiency. Figure 3 shows the power output of the WT in the non-down-regulation condition.

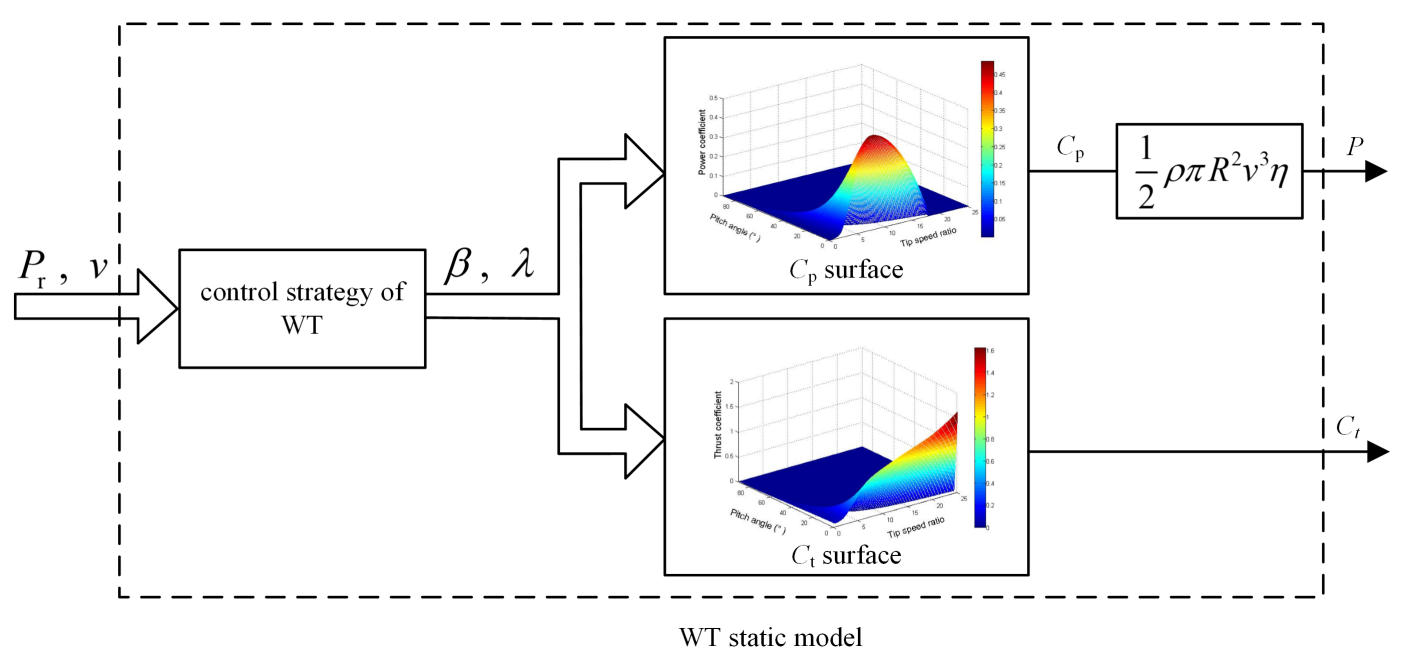

Figure 2. Wind turbine static model.

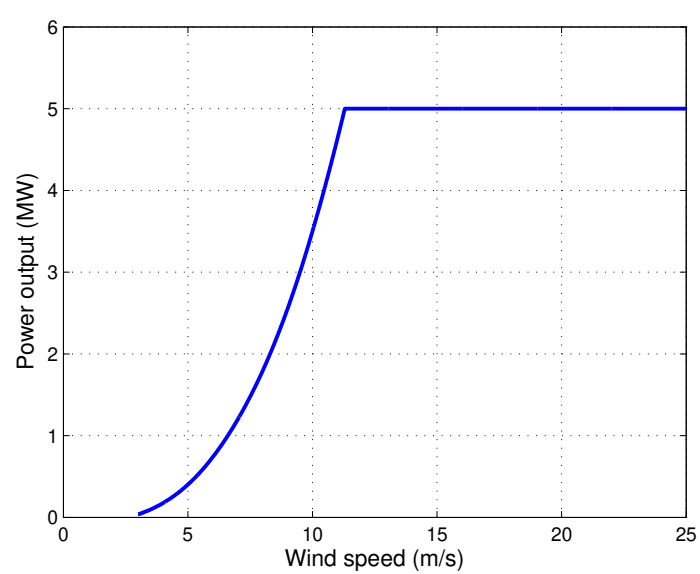

Figure 3. Power curve of the wind turbine in the non-down-regulation condition.

Because power dispatch and power optimization are involved in this paper, the down-regulation strategy of WTs has to be mentioned. The down-regulation strategy directly affects the operation state of the WT and further affects the aerodynamic interaction among the WTs. This is due to the fact that the $C_{\mathrm{t}}$ values are different when the $C_{\mathrm{p}}$ values are the same under different down-regulation strategies. The maximum $\omega$ strategy was adopted in the WT model. In this strategy, the rotor speed is set as the maximum value when the WT is down-regulated. One of the advantages of this strategy is that 
some of the energy is converted to the kinetic energy of the rotor. When the power reference is set to a higher value, the power recovery is fast. The specific operation state of the WT in this strategy is shown in Figure 4.

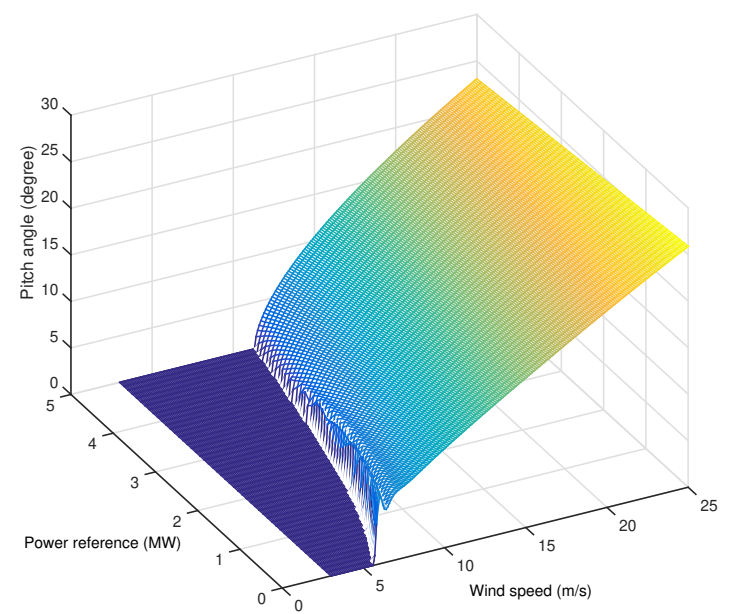

(a)

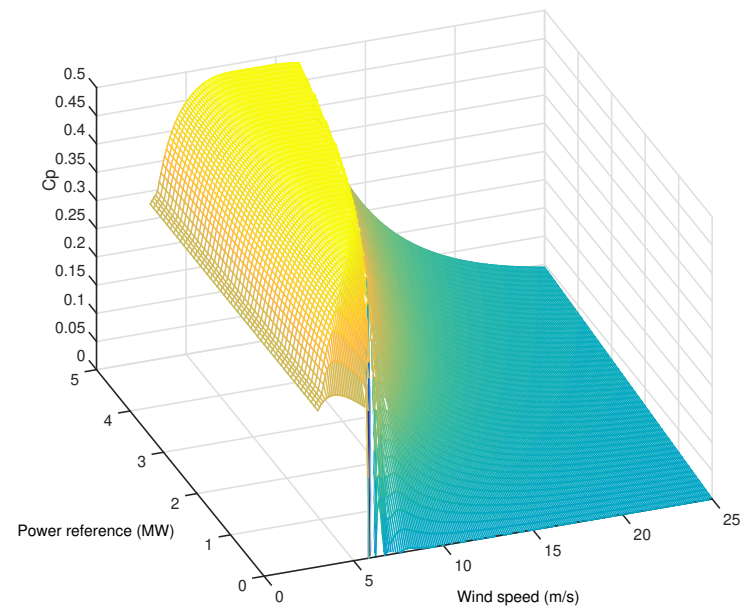

(c)

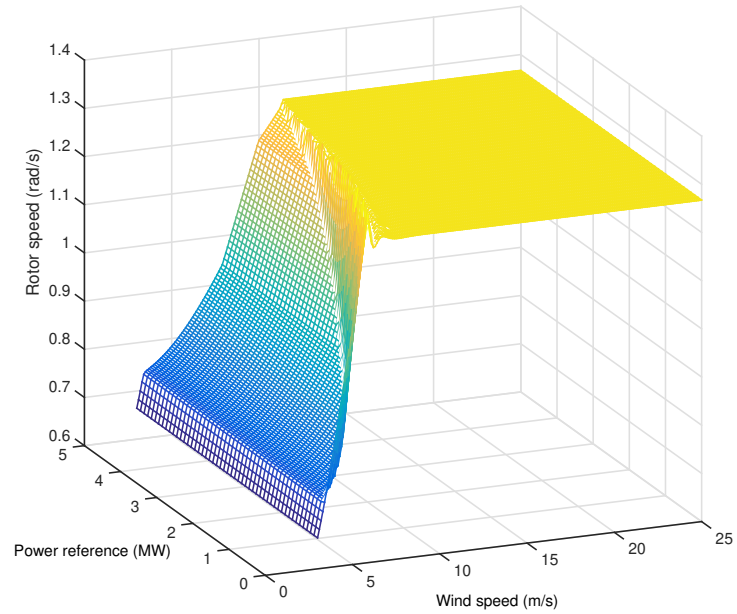

(b)

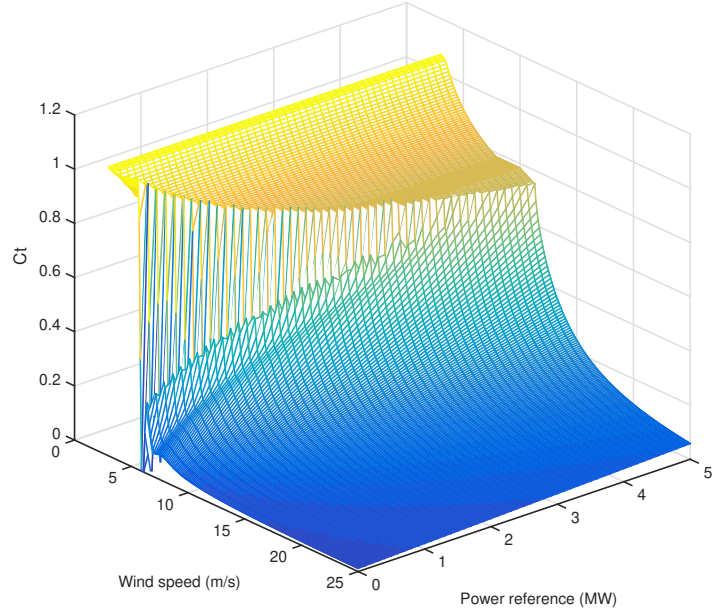

(d)

Figure 4. Operation state of WT in the maximum $\omega$ down-regulation strategy: (a) Pitch angle surface.

(b) Rotor speed surface. (c) $C_{\mathrm{p}}$ surface. (d) $C_{\mathrm{t}}$ surface.

The Figure $4 \mathrm{a}-\mathrm{d}$ are the pitch angle, rotor speed, and $C_{\mathrm{p}}$ and $C_{\mathrm{t}}$ surfaces, which respectively show the operation points of these four important operating parameters of the WT in the non-down-regulation and down-regulation conditions. The $x$ axis is the wind speed, the $y$ axis the power reference, and the $\mathrm{z}$ axis the respective surface for each graph. It can be seen from Figure $4 \mathrm{~b}$ that when the power reference is less than the available power, the rotor speed is adjusted to the maximum value.

\subsection{Wake Model}

The wake effect is the aerodynamic interaction among WTs in the WF. When the wind from upstream blows through the WT, and the wind energy in the downstream becomes smaller because the WT extracts a part of the energy from the wind. The result of this process produces a wake. The wake has two main effects. One is the wind velocity deficit, which decreases the available wind energy to the downstream WT. The other is the increase in turbulence, which aggravates the fatigue loads of the downstream WTs. Because this paper mainly studies the active power of the WF, only wind velocity 
deficit is considered here. To describe the wake effects in the WF model, the Jensen model was adopted for the single wake and the quadratic summation method for multiple wakes [21]. Although the Jensen model is not as accurate as the computational fluid dynamics model, the computational cost of the Jensen model is low. Therefore, it is very suitable for control. The Jensen model can be expressed as follows:

$$
\frac{v}{u}=\frac{1-\sqrt{1-C_{t}}}{(1-2 \alpha X / D)^{2}}
$$

where $v$ is the downwind wind speed at position $X, u$ is the ambient free wind speed, $X$ is the distance between upstream and downstream WT, $D$ is the diameter of the rotor, and $\alpha$ is the decay constant, choosing 0.05 for offshore WFs [22].

For multiple wakes, the velocity deficit of the $j$ th WT can be calculated as:

$$
\left(1-\frac{v_{j}}{u}\right)^{2}=\sum_{i=1}^{n}\left(1-\frac{v_{i j}}{u}\right)^{2}
$$

where $v_{j}$ is the wind speed of the $j$ th WT, $n$ is the number of wakes that the $j$ th WT is in, and $v_{\mathrm{ij}}$ is the wind speed of the $j$ th WT under the influence of the wake of the $i$ th WT.

\subsection{Wind Farm Layout}

Due to the wake losses, the layout directly affects the power production of the WF. It can be seen from the wake model that the smaller the spacing of the WTs, the larger the loss of the wind speed in the downstream WTs and the larger the power loss of the WF. However, if the spacing is too large, it will also lead to an increase in the investment costs. This is because the layout is not only related to the site area of the WF, but also because of the increase to the length of the electricity collector system cables. Therefore, the layout design is an optimization problem that should be solved in the design stage of the WF. There are many relevant research efforts on this topic [23]. Typically, the spacing of an offshore WF is in the range of $5 D-15 D$ [24], where $D$ represents the rotor diameter of the WTs.

It can be seen from Figure 6 that, even in the case of the full wake with the worst wake loss, the wind speed loss is very small after the fourth WT. Therefore, the layout of the WF adopted in this paper is five WTs arranged in a straight line with a 6.5-D spacing. This layout is sufficient to illustrate the characteristics of the offshore WF to verify the effectiveness of the proposed strategy. In order to highlight the influence of the wake, the wind direction is chosen to be 270 degrees, that is all the downstream WTs are in the full wake condition. The specific layout is shown in Figure 5. Figure 6 shows the wind speeds of five WTs in the full wake condition. The inflow wind speed of the first WT is $12 \mathrm{~m} / \mathrm{s}$. The wind velocity deficit can be seen clearly. The wind speed of the fifth WT drops to $9.24 \mathrm{~m} / \mathrm{s}$.

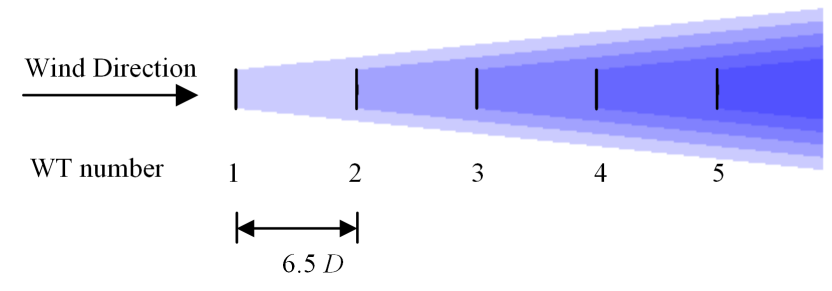

Figure 5. Wind farm layout. 


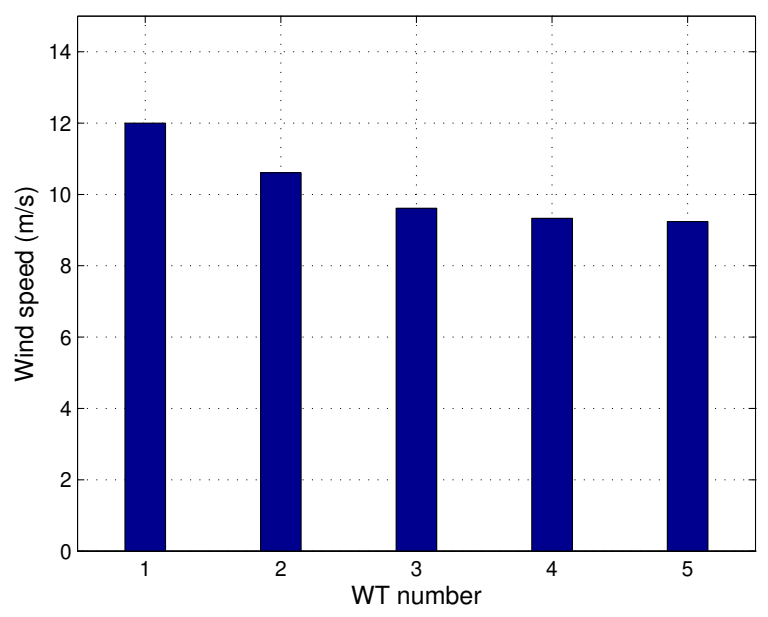

Figure 6. Distribution of the wind speed of the five-WT wind farm with a 6.5-D spacing.

\section{Generator Cooling System Fault}

On MW-class WTs, the temperature of the generator windings is monitored by the temperature sensor. However, the sensor cannot monitor all the spots on the windings. In addition, because the structure of the generator is complicated, it is difficult to obtain an accurate temperature distribution. In [25], a simplified thermal model was used to estimate the temperature, as shown in Figure 7. In this model, the power loss of the stator winding, $P_{\text {loss }}$ is the heat source, $R_{\mathrm{th}}$ is the thermal resistance, $C_{\mathrm{th}}$ is the thermal capacity, $\theta_{\mathrm{amb}}$ is the ambient temperature, and $\theta$ is the temperature of the stator winding.

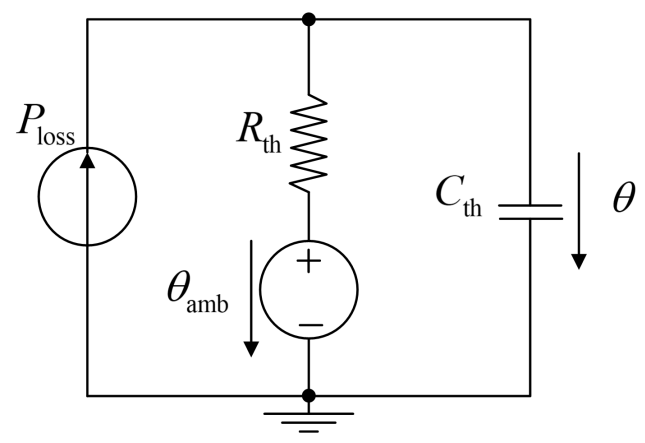

Figure 7. Simplified thermal model of the generator.

The $P_{\text {loss }}$ of the stator winding can be expressed as:

$$
P_{\text {loss }}=I_{\mathrm{s}}^{2} R_{\mathrm{s}}
$$

where $I_{\mathrm{S}}$ is the current of the stator winding and $R_{\mathrm{S}}$ is the resistance of the stator winding. The power loss curve is shown in Figure 8.

According to the steady-state analysis of the thermal model, the following equation can be obtained:

$$
\theta=P_{\text {loss }} R_{\mathrm{th}}+\theta_{\mathrm{amb}}
$$

The steady-state winding temperature depends on $P_{\text {loss }}, R_{\mathrm{th}}$, and $\theta_{\mathrm{amb}}$. Assuming $\theta_{\mathrm{amb}}$ is a constant, $P_{\text {loss }}$ and $R_{\text {th }}$ will determine the steady-state winding temperature. Therefore, the temperature rise $\Delta \theta$ can be expressed as (6):

$$
\Delta \theta=P_{\text {loss }} R_{\text {th }}
$$

When the cooling system is faulty, its cooling capacity decreases. This will lead to a high temperature and a low efficiency of the generator. According to [26], if the coolant in the cooling system does not change, faults can be equivalent to an increase in $R_{\mathrm{th}}$. To protect the $\mathrm{WT}$, the power 
should be limited to the power value that occurs when the faulty generator reaches the temperature rise of the healthy generator at full load.

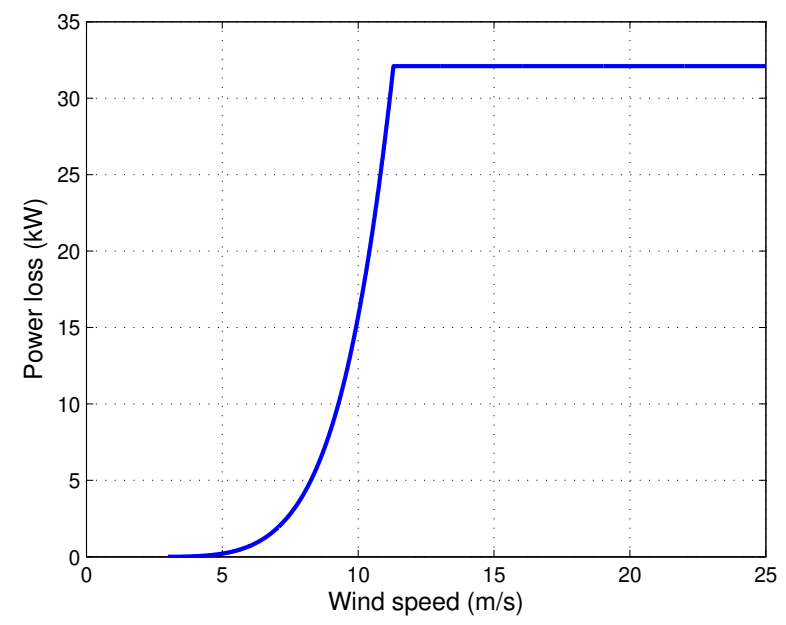

Figure 8. Power loss curve.

The parameters in the thermal model can be estimated from the model and the actual measured data. When the fault occurs, a specific power limit value can be calculated based on the model parameters. Assuming the $R_{\mathrm{th}}$ is $0.003 \mathrm{~K} / \mathrm{W}$ in normal conditions, the normal temperature rise at the rated power of the generator is $96 \mathrm{~K}$. Then, we can get the curves displayed in Figure 9. In order to ensure that the temperature rise of the stator winding does not exceed the value of the rated power in the normal condition, the power limits corresponding to $R_{\mathrm{thA}}, R_{\mathrm{thB}}$, and $R_{\mathrm{thC}}$ are $P_{l A}, P_{l B}$, and $P_{l C}$, respectively.

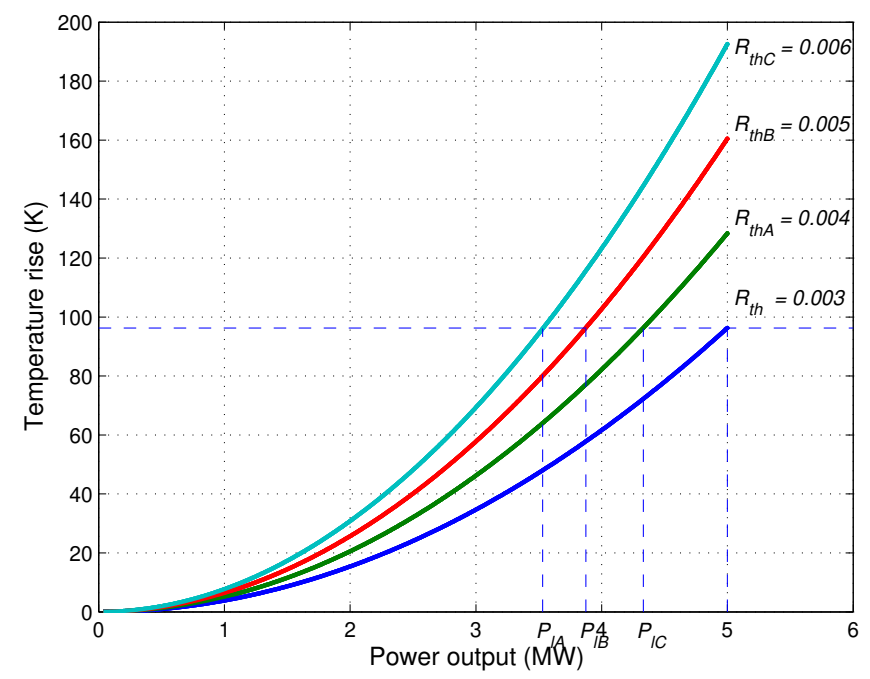

Figure 9. Temperature rise curves under different thermal resistances.

\section{Optimal Power Dispatch with Fault Accommodation}

According to the previous sections, the objectives of optimal active power dispatch under generator faults can be divided into the following:

- When a fault occur on the WT, the safety of the WT is the most important.

- The power output of the WF should follow the power demand from the TSO as much as possible.

- Through the reasonable power dispatch strategy, the power losses caused by the wake can be reduced. 
- The power fluctuation of the WTs due to the power dispatch strategy should be reduced as much as possible.

In this paper, the optimization process of active power dispatch is actually a process of solving nonlinear constrained multi-objective optimization problems. If the number of WTs is small and the controller's computing capacity is high enough, the enumeration method can find the optimal solution that meets the requirements after calculating each power reference vector. However, this algorithm will take a long time when the number of WTs increases. PSO is an optimization algorithm that has been applied in many engineering applications. Compared with other optimization methods, PSO has the advantages of less adjustable parameters, fast convergence, and easy programming. Therefore, we adopted the PSO algorithm to optimize the power dispatch of the WF.

\subsection{Particle Swarm Optimization}

PSO is a heuristic algorithm introduced by James Kennedy and Russell Eberhart in 1995. It is an optimization algorithm for simulating bird predation behavior. PSO has many advantages, such as simple implementation, few adjustable parameters, and fast convergence [27]. It has been widely used in function optimization, neural network training, and many other related engineering applications. The basic PSO algorithm can be expressed as follows:

It is assumed that $N$ particles in an $n$-dimensional space constitute a population. The position $\boldsymbol{X}_{i}$, the velocity $\boldsymbol{V}_{i}$, the optimal position $\boldsymbol{P}_{i}^{L}$ searched by itself of the $i$ th particle, and the optimal position $\boldsymbol{P}_{g}$ of the entire population are respectively recorded as: $\boldsymbol{X}_{i}=\left(x_{i 1}, \ldots, x_{i n}\right), \boldsymbol{V}_{i}=\left(v_{i 1}, \ldots, v_{i n}\right)$, $\boldsymbol{P}_{i}^{L}=\left(p_{i 1}, \ldots, p_{i n}\right)$, and $\boldsymbol{P}_{g}=\left(p_{g 1}, \ldots, p_{g n}\right)$. The objective value can be calculated by taking $\boldsymbol{X}_{i}$ into the objective function. Firstly, $\boldsymbol{X}_{i}$ and $\boldsymbol{V}_{i}$ are randomly initialized. Then, the search process is conducted by updating (7) and (8):

$$
\begin{gathered}
\boldsymbol{V}_{i}=w \boldsymbol{V}_{i}+c_{1} r_{1}\left(\boldsymbol{P}_{i}^{L}-\boldsymbol{X}_{i}\right)+c_{2} r_{2}\left(\boldsymbol{P}_{g}-\boldsymbol{X}_{i}\right) \\
\boldsymbol{X}_{i}=\boldsymbol{X}_{i}+\boldsymbol{V}_{i}
\end{gathered}
$$

where $i$ is the number of the particle, $w$ is the inertia weight, $c_{1}$ and $c_{2}$ are learning factors, and $r_{1}$ and $r_{2}$ are random numbers uniformly distributed between $(0,1)$.

PSO has been proven to be effective for many different optimization problems. However, the original PSO is proposed for the single objective continuous problem. In order to solve the constrained multi-objective optimization problem that is common in practical applications, the basic PSO should be modified [28,29].

\subsection{Fault Accommodation and Optimization}

It can be seen that the problem in this paper is a constrained multi-objective optimization problem from the objectives summarized at the beginning of this section. In order to achieve these objectives, the PSO algorithm applied to power dispatch of the WF should be implemented by formulating the problem as:

$$
\begin{aligned}
& \min \frac{\left|\sum_{i=1}^{n} P_{i}(k)-P_{\mathrm{dem}}(k)\right|}{P_{\mathrm{dem}}(k)} * k 1+(1-\mathrm{r}(\boldsymbol{P}(k-1), \boldsymbol{P}(k))) * k 2+\frac{\sum_{i=1}^{n}\left|P_{\mathrm{r}, i}(k)-P_{i}(k)\right| / P_{\mathrm{r}, i}(k)}{n} * k 3 \\
& \text { s.t. }\left\{\begin{array}{l}
0 \leq P_{\mathrm{r}, i}(k) \leq P_{\mathrm{rated}}, \quad \text { if } i \text { th } \mathrm{WT} \text { is in a healthy condition, } \\
0 \leq P_{\mathrm{r}, i}(k) \leq P_{\text {limit },} \quad \text { if } i \text { th WT is in a faulty condition. }
\end{array}\right.
\end{aligned}
$$

where $n$ is the number of WTs, $P_{\mathrm{r}, i}(k)$ is the power reference of the $i$ th WT at time $k$ (also the optimized variable), $P_{\text {rated }}$ is the rated power output of the WT, $P_{i}(k)$ is the power output of the $i$ th WT at time $k$, $\boldsymbol{P}(k)$ is the power output vector at time $k$, and $P_{\text {dem }}(k)$ is the power demand from TSO at time $k$.

From the constraints, it can be seen that the power reference of the faulty turbine will be limited to the specific power limit that can be calculated based on the thermal model in Section 3. The power limit is set as the upper boundary of the optimized variable of the faulty WT, so the power reference 
will not exceed the power limit. This also means that the faulty turbine will not produce more power than the power limit, and the WT's fault will not deteriorate further.

The first term in the objective function indicates the degree of deviation between the power output of the WF and the power demand. For the active power control of the WF, tracking the reference from the TSO is a basic function and has a high priority. Hence, it has a large weight in the objective function. From this term, it is obvious that we care more about the total power output from WF than the power of individual WTs in WFC. This means that there is much flexibility to dispatch the power of each WT while ensuring the WF power output meets the power demand.

Although the wake loss reduction is not directly contained in the objective function, the power output of the WF will also try to follow the power demand even if the power demand is high. Therefore, tracking a high power demand also means the power maximization. The effect of the power improvement was verified in Section 5 .

When the power demand is lower than the available power of the WF, there will be many situations that meet the required power tracking. Moreover, the initialization of PSO includes a random process. Therefore, the output from PSO in this state may be quite different from the previous state. If this happens, it will cause the power fluctuation of the WT to become larger. It should be noted that the power fluctuation here does not refer to the dynamic change of power, but the change of power when the WF model changes from one static state to another. In order to reduce this power fluctuation, we added the second term of the objective function. Here, the correlation coefficient of $P_{i}(k)$ and $P_{i}(k-1)$ is calculated, and then, the value will be subtracted by one. If there is no fluctuation, the value of this term is zero. The larger this value, the larger the fluctuation. The expression of the correlation coefficient is shown in (10).

$$
\mathrm{r}(\boldsymbol{P}(k-1), \boldsymbol{P}(k))=\frac{\operatorname{cov}(\boldsymbol{P}(k-1), \boldsymbol{P}(k))}{\operatorname{std}(\boldsymbol{P}(k-1)) \cdot \operatorname{std}(\boldsymbol{P}(k))}
$$

where $\operatorname{cov}\left(\boldsymbol{P}_{i}(k), \boldsymbol{P}(k-1)\right.$ is the covariance of $\boldsymbol{P}(k)$ and $\boldsymbol{P}(k-1)$ and $\operatorname{std}(P(k))$ and $\operatorname{std}(\boldsymbol{P}(k-1))$ are the standard deviations of $\boldsymbol{P}(k)$ and $\boldsymbol{P}(k-1)$.

According to the WT model, if the power reference is larger than the available power, the WT can only produce power as large as the available power. When the control strategy and the properties of the WT are fixed, the available power depends on the wind speed. Due to the wake effect, the wind speed of the downstream WT is affected by the upstream WT. Therefore, the wind speed of the downstream WT can only be obtained after the operating state of the upstream WT is determined. During the iterative process of PSO, the selection of $P_{\mathrm{r}, i}(k)$ does not take the available power into account. There will be many solutions with the power reference in excess of the available power. This will also affect the optimization process. In order to avoid this situation, a penalty function was added as the third term of the objective function, which represents the deviation between power references and power outputs of all WTs. With this approach, many unreasonable power references can be removed.

Through the objective function and its constraints, all the objectives of the optimal power dispatch strategy under generator faults can be achieved. The control diagram of the power dispatch is shown in Figure 10. When the WF controller receives the power demand from the TSO, the optimal power references will be calculated and then sent to all the WTs according to the proposed power dispatch strategy. All the WTs will track these power references by their original turbine controllers. The power output signals will be fed back to the WF controller for the optimization process in the next static state. 


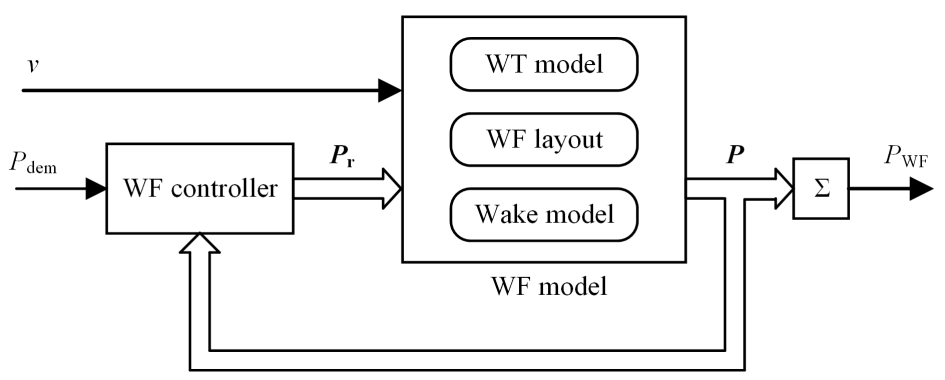

Figure 10. Control diagram of power dispatch.

\subsection{Proportional Dispatch Strategy}

As a baseline wind farm control strategy, PDS was introduced in [18]. In this strategy, the WF controller distributes the power demand to the WTs based on the proportion of each WT's available power. It can be expressed as (11).

$$
P_{\mathrm{r}, i}=\frac{P_{\mathrm{a}, i}}{\sum_{i=1}^{n} P_{\mathrm{a}, i}} P_{\mathrm{dem}}
$$

where $P_{\mathrm{a}, i}$ is the available power of the $i$ th WT.

Certain characteristics of PDS can be determined. First, power demand can be easily distributed to the individual WTs. Power reference depends on the proportion of the WT's available power. Second, this strategy does not consider the aerodynamic interaction among all the WTs, so it is not an optimal way to dispatch the reference. In other words, WFs still have the ability to produce more power. Finally, PDS does not consider the fault condition. The faulty WT can only be controlled to continue running or shut down by the WF operator manually.

\section{Case Study}

In order to verify the effectiveness of the proposed Optimal Dispatch Strategy (ODS), the cases were simulated to explain the effects of ODS from three aspects: power generation capacity, power fluctuation, and fault accommodation. In Case 1, all the WTs were in the normal condition, which means no fault occurred. The power generation capacity of the WF in ODS was compared with that in PDS. In Case 2, WF operated in the normal condition, as well as in ODS, but $k 2$ in the objective function took different values. In Case 3, a WT had a generator cooling system fault. The proposed ODS was compared with two different fault-handling methods in PDS.

The WF and strategies used here are described in Sections 2 and 3. After many trials and adjustments, the weight factors in objective functions: $k 1, k 2, k 3$ are set to $10,4,3$, respectively. The parameters of the WT are shown in Table 1.

Table 1. Parameters of NREL 5-MW wind turbine.

\begin{tabular}{ll}
\hline Parameter & Value \\
\hline Rated Power & $5 \mathrm{MW}$ \\
Rotor Diameter & $126 \mathrm{~m}$ \\
Min. and Max. Rotor Speed & $6.9 \mathrm{rpm}, 12.1 \mathrm{rpm}$ \\
Cut-in, Rated, Cut-out Wind Speed & $3 \mathrm{~m} / \mathrm{s}, 11.4 \mathrm{~m} / \mathrm{s}, 25 \mathrm{~m} / \mathrm{s}$ \\
Gearbox Ratio & $97: 1$ \\
Synchronous Frequency & $50 \mathrm{~Hz}$ \\
Electrical Generator Efficiency & $94.4 \%$ \\
Number of Pole-pairs & 3 \\
\hline
\end{tabular}

\subsection{Case 1: Comparison of Power Generation Capacity}

In Case 1, the wind speed and $P_{\text {dem }}$ were set to $12 \mathrm{~m} / \mathrm{s}$ and $18 \mathrm{MW}$. All WTs were operating in the normal condition. PDS does not consider the wake effect and only distributes the power demand 
proportionally according to the available power of WT. If we only focus on power, when the power demand is lower than the maximum output of the WF in this strategy, this strategy is feasible. However, when the power demand is higher than the maximum output of the WF in this strategy, the WF cannot produce more power. In ODS, although the optimization algorithm does not directly consider the wake effect, the power demand appears in the objective function. The PSO algorithm searches the optimal solution to track the power demand as close as possible.

The simulation result is shown in Table 2 and Figure 11.

Table 2. Comparison of power generation capacity in Case 1. PDS, Proportional Dispatch Strategy.

\begin{tabular}{cccccc}
\hline & \multicolumn{2}{c}{ PDS } & & \multicolumn{2}{c}{ ODS } \\
\cline { 2 - 3 } \cline { 5 - 6 } & $\boldsymbol{P}_{\mathbf{r}} \mathbf{( M W )}$ & $\boldsymbol{P} \mathbf{( M W )}$ & & $\boldsymbol{P}_{\mathbf{r}} \mathbf{( M W )}$ & $\boldsymbol{P} \mathbf{( M W )}$ \\
\hline WT1 & 5.00 & 5.00 & & 5.00 & 5.00 \\
WT2 & 4.20 & 4.17 & & 4.17 & 4.17 \\
WT3 & 3.13 & 3.11 & & 3.01 & 3.01 \\
WT4 & 2.86 & 2.84 & & 3.00 & 3.00 \\
WT5 & 2.78 & 2.76 & & 2.81 & 2.81 \\
\hline$P_{\mathrm{WF}}$ & 18.00 & 17.88 & & 18.00 & 18.00 \\
\hline
\end{tabular}

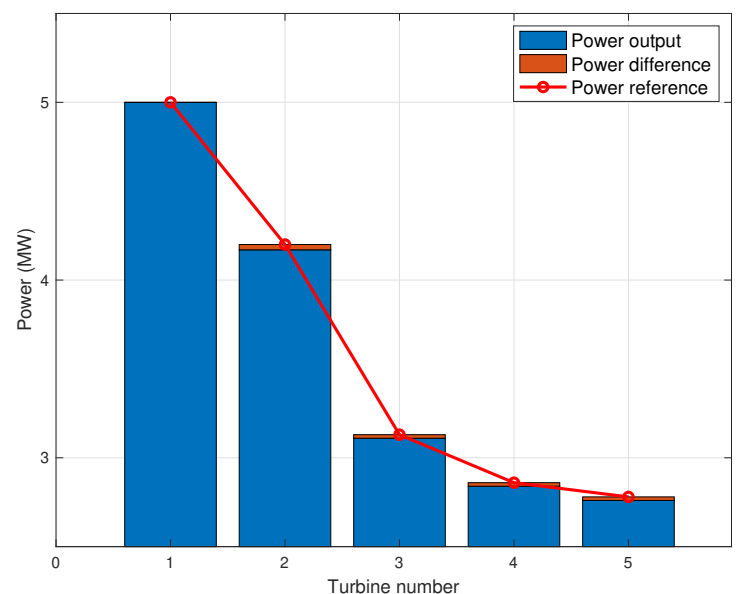

(a)

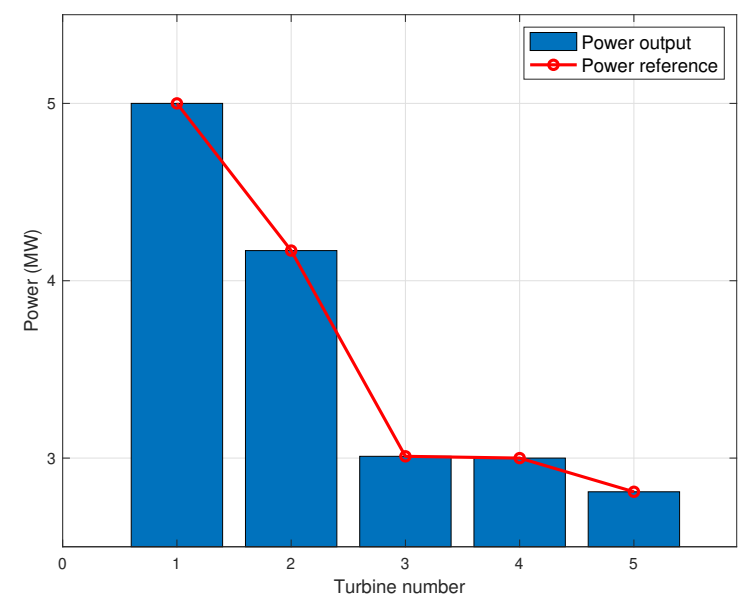

(b)

Figure 11. Comparison of power generation capacity in Case 1: (a) power reference and power output in PDS; (b) power reference and power output in ODS.

It can be seen that the WF can only produce 17.88 MW in PDS, but the power demand was $18 \mathrm{MW}$. The red bar shows the power difference between the power reference and the power output. However, through PSO, ODS can improve the power generation capacity of the WF and follow the power demand.

\subsection{Case 2: Comparison of Power Fluctuation}

In Case 2, the wind speed was set to $12 \mathrm{~m} / \mathrm{s}$. $P_{\text {dem }}$ was $17 \mathrm{MW}$ in the first state and changed to $16 \mathrm{MW}$ in the next state. To illustrate the effect of the power fluctuation term in the objective function, the WF operated twice in ODS. For the first time, $k 2$ was set to zero, which means that the power fluctuation was not taken into account. For the second time, $k 2$ was set to four. Then, the results of these two time simulations were compared. The result is shown in Table 3 and Figure 12. 
Table 3. Comparison of power fluctuation in Case 2.

\begin{tabular}{ccccccc}
\hline & \multicolumn{2}{c}{ ODS, $\boldsymbol{k} \mathbf{2}=\mathbf{0}$} & & \multicolumn{2}{c}{ ODS, $\boldsymbol{k} \mathbf{2}=\mathbf{4}$} \\
\cline { 2 - 3 } \cline { 5 - 6 } \cline { 5 - 6 }$P_{\text {dem }}$ & 17.00 & 16.00 & & 17.00 & 16.00 \\
\hline WT1 & 5.00 & 4.82 & & 5.00 & 5.00 \\
WT2 & 4.17 & 4.25 & & 4.17 & 4.17 \\
WT3 & 2.81 & 2.01 & & 2.81 & 2.51 \\
WT4 & 2.61 & 1.51 & & 2.61 & 2.21 \\
WT5 & 2.41 & 3.41 & & 2.41 & 2.11 \\
\hline$P_{\text {WF }}$ & 17.00 & 16.00 & & 17.00 & 16.00 \\
\hline $\mathrm{r}\left(\boldsymbol{P}, \boldsymbol{P}^{\prime}\right)$ & \multicolumn{3}{c}{0.8161} & & \multicolumn{2}{c}{0.9987} \\
\hline
\end{tabular}

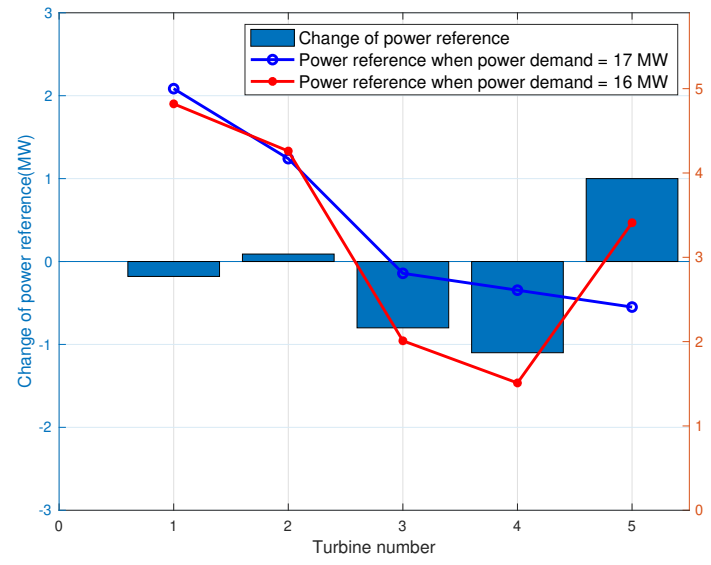

(a)

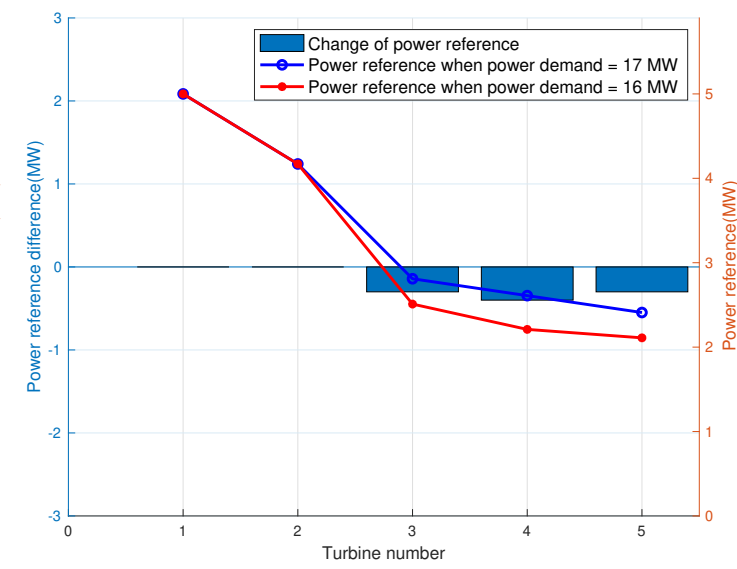

$(\mathbf{b})$

Figure 12. Comparison of power fluctuation in Case 2: (a) power references in ODS $(k 2=0)$; (b) power references in ODS $(k 2=4)$.

When $k 2=0$ and the power demand is smaller than the available power of the WF, many different power reference combinations can be used as the final result. Because the PSO algorithm itself is a random process, this may result in a large change in the power reference of the WT between two states. The large change of power reference of WT5 in PDS is a good illustration to explain the impact of the random process in PSO on power fluctuation.

When $k 2=4$, power fluctuation is one of the optimization objectives. The power reference of the next state will be as close as possible to that of the previous state. The correlation coefficient of the power references between the two states can be used to evaluate the degree of the power change. The larger the correlation coefficient, the smaller the power fluctuation. The correlation coefficient was improved from 0.8161 to 0.9987 .

\subsection{Case 3: Comparison of Fault Handling}

Generally, when a fault occurs on WT, the WF operator selects a specific fault-handling method according to the fault alarm. However, there are only two general methods: one is to let the faulty WT run in the original state, which is marked as M1, and the other is to directly shut down the faulty WT, which is marked as M2. In Case 3, the wind speed and $P_{\text {dem }}$ were set to $12 \mathrm{~m} / \mathrm{s}$ and $17 \mathrm{MW}$. Assuming the fault occurred on the WT2, $R_{\text {th }}$ changed from $0.003 \mathrm{~K} / \mathrm{W}-0.006 \mathrm{~K} / \mathrm{W}$. According to the thermal model in Section 3, the temperature rise of the generator at full load (TR) was $96 \mathrm{~K}$ and the corresponding power limit was 3.53 MW. We compared the two fault handling methods in PDS with ODS. The result is shown in Tables 4 and 5 and Figures 13 and 14. 
Table 4. Comparison of power and temperature rise in Case 3, M1.

\begin{tabular}{lcclcc}
\hline & \multicolumn{2}{c}{ PDS } & & \multicolumn{2}{c}{ ODS } \\
\cline { 2 - 3 } \cline { 5 - 6 } & $\boldsymbol{P}_{\mathbf{r}} \mathbf{( M W )}$ & $\boldsymbol{P}$ (MW) & & $\boldsymbol{P}_{\mathbf{r}}$ (MW) & $\boldsymbol{P}$ (MW) \\
\hline WT1 & 3.87 & 3.87 & & 5.00 & 5.00 \\
WT2 & 3.62 & 3.62 & & 3.53 & 3.53 \\
WT3 & 3.25 & 3.25 & & 3.01 & 3.01 \\
WT4 & 3.13 & 3.13 & & 2.81 & 2.81 \\
WT5 & 3.13 & 3.13 & & 2.64 & 2.64 \\
\hline$P_{\text {WF }}$ & 17.00 & 17.00 & & 17.00 & 17.00 \\
\hline$\Delta \theta(\mathrm{K})$ & \multicolumn{3}{c}{100.95} & \multicolumn{3}{c}{96.00} \\
\hline
\end{tabular}

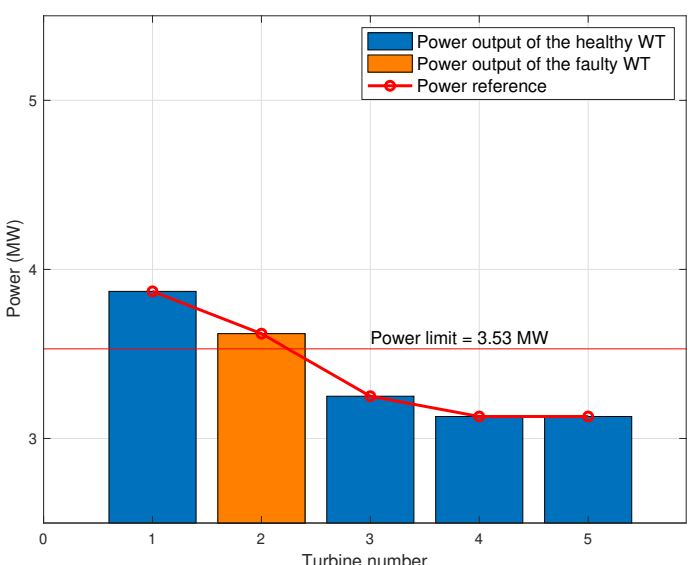

(a)

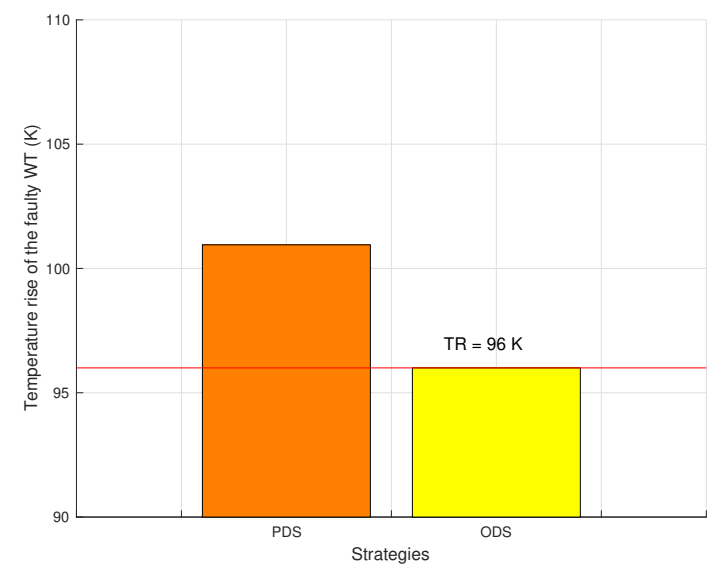

(c)

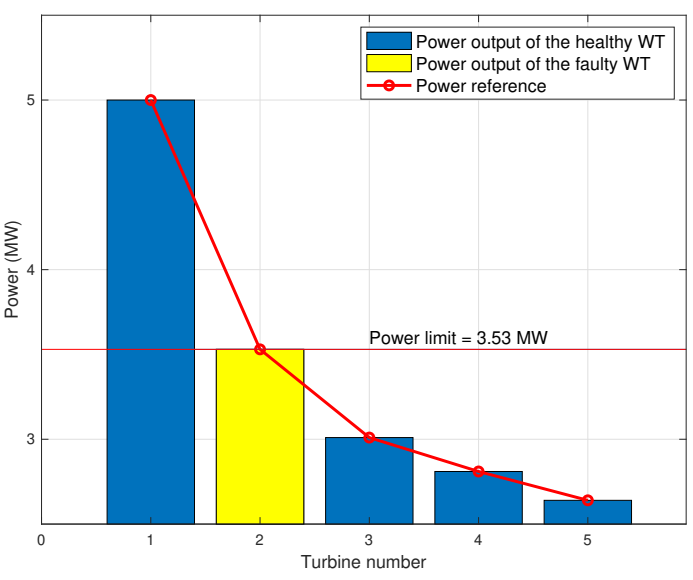

(b)

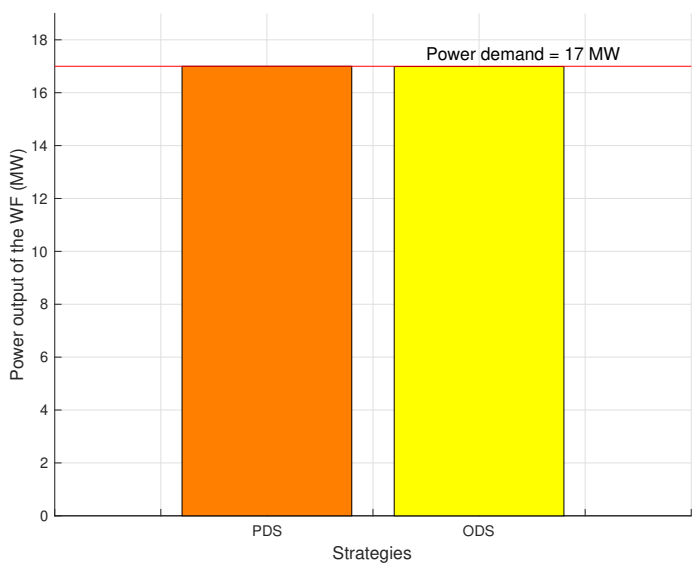

(d)

Figure 13. Comparison of power and temperature rise in Case 3, M1: (a) power reference and power output in PDS; (b) power reference and power output in ODS; (c) temperature rises of the faulty WT in PDS and ODS; (d) power output of the WF.

When M1 was taken, the faulty WT continued to operate as normal. Therefore, the temperature rise increased from $96.00 \mathrm{~K}$ to $100.95 \mathrm{~K}$ due to the increase of $R_{\mathrm{th}}$. Long-term over-temperature operation will reduce the lifetime of the coil isolation and the efficiency of the generator. In ODS, the faulty turbine was down-regulated to the power limit. The result shows that both PDS and ODS can track the power demand very well. However, the temperature rise of the faulty WT exceeded 96 K in PDS. 
Table 5. Comparison of power and temperature rise in Case 3, M2.

\begin{tabular}{lcclccc}
\hline & \multicolumn{2}{c}{ PDS } & & \multicolumn{2}{c}{ ODS } \\
\cline { 2 - 3 } \cline { 5 - 6 } \cline { 5 - 6 } & $\boldsymbol{P}_{\mathbf{r}} \mathbf{( M W )}$ & $\boldsymbol{P}$ (MW) & & $\boldsymbol{P}_{\mathbf{r}}$ (MW) & $\boldsymbol{P}$ (MW) \\
\hline WT1 & 5.00 & 5.00 & & 5.00 & 5.00 \\
WT2 & 0 & 0 & & 3.53 & 3.53 \\
WT3 & 5.00 & 5.00 & & 3.01 & 3.01 \\
WT4 & 3.71 & 3.25 & & 2.81 & 2.81 \\
WT5 & 3.29 & 2.88 & & 2.64 & 2.64 \\
\hline$P_{\mathrm{WF}}$ & 17.00 & 16.13 & & 17.00 & 17.00 \\
\hline$\Delta \theta(\mathrm{K})$ & \multicolumn{3}{c}{0} & \multicolumn{3}{c}{96.00} \\
\hline
\end{tabular}

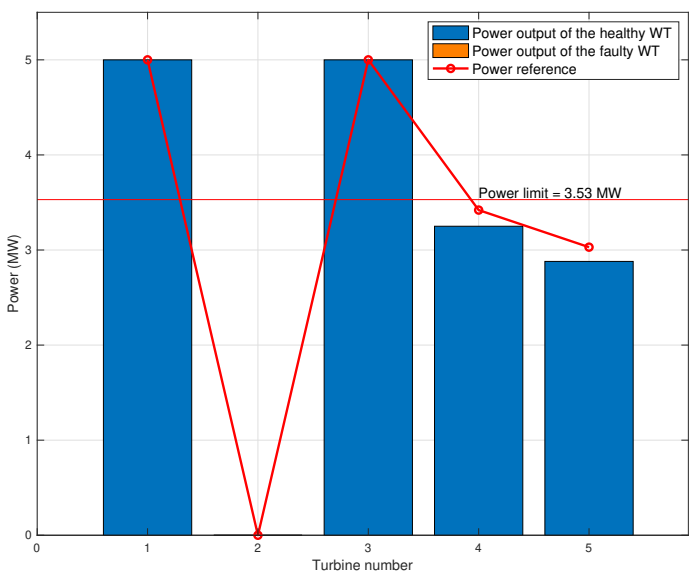

(a)

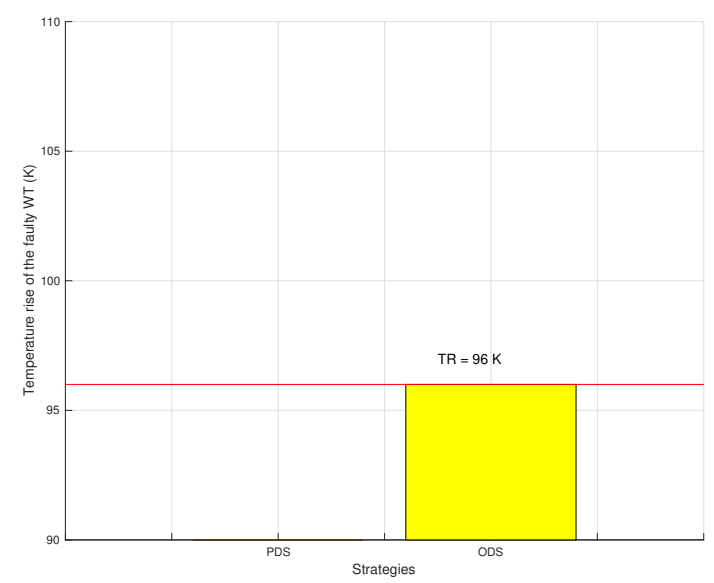

(c)

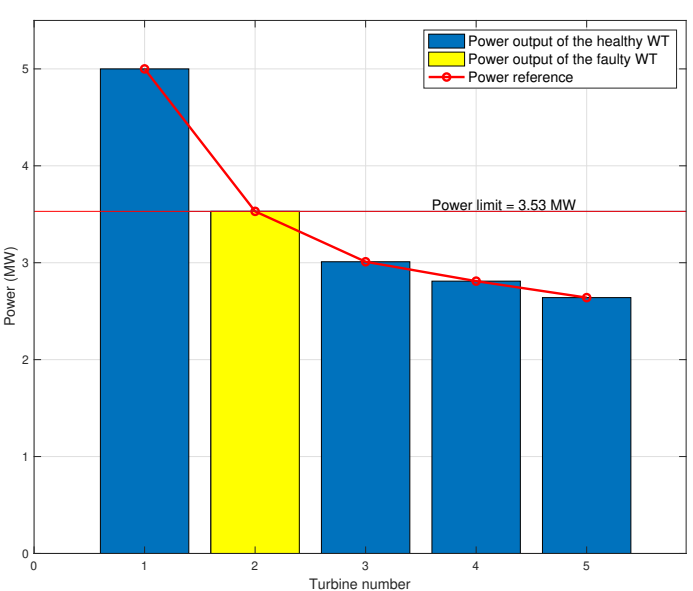

(b)

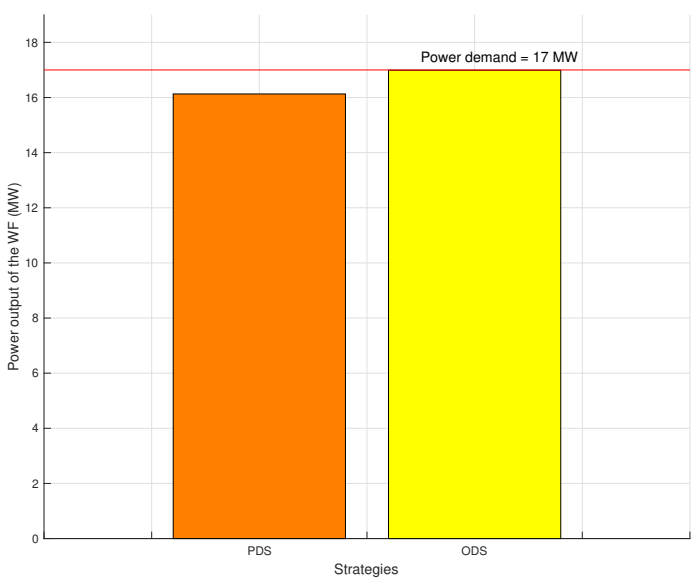

(d)

Figure 14. Comparison of power and temperature rise in Case 3, M2: (a) power reference and power output in PDS; (b) power reference and power output in ODS; (c) temperature rises of the faulty WT in PDS and ODS; (d) power output of the WF.

When M2 was taken, the faulty turbine was shut down. Therefore, the temperature rise of the generator became zero. This method can protect the WT from further damage. However, the power output of WF decreased to $16.13 \mathrm{MW}$. The sudden drop of the WF power will also have a bad effect on the grid. It can be seen that PDS and the general fault-handling methods can only choose one option from power production and fault protection. However, an efficient trade-off can be obtained through ODS. 


\section{Conclusions}

An optimal active power dispatch strategy was developed in this paper to improve the power generation capacity and get an efficient trade-off between power production and fault protection. First, the power limit, which can protect the fault from further damage, was calculated by the thermal model of the generator. Then ODS was proposed to optimize the power references to the WTs by PSO with the consideration of the wake effect and the power limit of the faulty WT. A multi-objective optimization problem was addressed by adding power demand tracking, power fluctuation, and the power difference between the power reference and power output to the objective function. Two general fault-handling methods and PDS were compared with the proposed strategy, and the result showed the effectiveness of the proposed strategy. This idea can be used for the other heat-related faults of the WT, as well. Further research should consider the maintenance schedule and other common faults of the generator, such as the turn-to-turn short-circuit fault of the generator. In addition, the WFC considering the lifetime of the parts in the WT will further improve the reliability of the WF and reduce the maintenance costs.

Author Contributions: Conceptualization, K.M., J.Z. and M.S.; writing-original draft, K.M.; writing-review and editing, J.Z., M.S., A.H. and Z.C.

Acknowledgments: The authors gratefully acknowledge financial support from Aalborg University and Otto Mønsteds Fond.

Conflicts of Interest: The authors declare no conflict of interest.

\section{References}

1. Sørensen, P.; Hansen, A.; Iov, F. Wind Farm Models and Control Strategies; Risø-R-146 Report; Risø: Roskilde, Denmark; 2005; Volume 1464, p. 63. [CrossRef]

2. Archer, C.L.; Vasel-Be-Hagh, A.; Yan, C.; Wu, S.; Pan, Y.; Brodie, J.F.; Maguire, A.E. Review and evaluation of wake loss models for wind energy applications. Appl. Energy 2018, 226, 1187-1207. [CrossRef]

3. Marden, J.R.; Ruben, S.D.; Pao, L.Y. A model-free approach to wind farm control using game theoretic methods. IEEE Trans. Control Syst. Technol. 2013, 21, 1207-1214. [CrossRef]

4. Serrano González, J.; Burgos Payán, M.; Riquelme Santos, J.; González Rodríguez, Á.G. Maximizing the overall production of wind farms by setting the individual operating point of wind turbines. Renew. Energy 2015, 80, 219-229. [CrossRef]

5. González, J.S.; Payán, M.B.; Santos, J.R. Optimum wind turbines operation for minimizing wake effect losses in offshore wind farms. In Proceedings of the 2013 13th International Conference on Environment and Electrical Engineering, Wroclaw, Poland, 1-3 November 2013; pp. 188-192. [CrossRef]

6. Kanev, S.K.; Savenije, F.J. Active Wake Control: Loads Trends; Technical Report January; ECN: Petten, The Netherlands; 2015.

7. Gebraad, P.; Teeuwisse, F.; Van Wingerden, J.; Fleming, P.A.; Ruben, S.; Marden, J.; Pao, L. Wind plant power optimization through yaw control using a parametric model for wake effects-A CFD simulation study. Wind Energy 2016, 19, 95-114. [CrossRef]

8. De La Peña, D.M.; Alamo, T.; Ramírez, D.R.; Camacho, E.F. Survey of wind farm control—Power and fatigue optimization. IFAC Proc. Vol. 2005, 16, 263-268. [CrossRef]

9. Yang, B.; Liu, R.; Chen, X. Fault Diagnosis for a Wind Turbine Generator Bearing via Sparse Representation and Shift-Invariant K-SVD. IEEE Trans. Ind. Inform. 2017, 13, 1321-1331. [CrossRef]

10. Lu, B.; Li, Y.; Wu, X.; Yang, Z. A review of recent advances in wind turbine condition monitoring and fault diagnosis. In Proceedings of the 2009 IEEEPower Electronics and Machines in Wind Applications, Lincoln, NE, USA, 24-26 June 2009; pp. 1-7.

11. García Márquez, F.P.; Tobias, A.M.; Pinar Pérez, J.M.; Papaelias, M. Condition monitoring of wind turbines: Techniques and methods. Renew. Energy 2012, 46, 169-178. [CrossRef]

12. Arabian-hoseynabadi, H.; Oraee, H.; Tavner, P.J. Electrical Power and Energy Systems Failure Modes and Effects Analysis ( FMEA ) for wind turbines. Int. J. Electr. Power Energy Syst. 2010, 32, 817-824. [CrossRef] 
13. Odgaard, P.F.; Stoustrup, J.; Kinnaert, M. Fault-tolerant control of wind turbines: A benchmark model. IEEE Trans. Control Syst. Technol. 2013, 21, 1168-1182. [CrossRef]

14. Badihi, H.; Zhang, Y.; Hong, H. Fault-tolerant cooperative control in an offshore wind farm using model-free and model-based fault detection and diagnosis approaches. Appl. Energy 2017, 201, 284-307. [CrossRef]

15. Reder, M.; Dennis, Elena, G.; Julio, J.M. Wind turbine failures-tackling current problems in failure data analysis. In Journal of Physics: Conference Series; IOP Publishing: Bristol, UK, 2016; p. 072027.

16. Kulkarni, S.V.; Khaparde, S. Transformer Engineering: Design and Practice; CRC Press: Boca Raton, FL, USA, 2004.

17. Borchersen, A.B.; Kinnaert, M. Model-based fault detection for generator cooling system in wind turbines using SCADA data. Wind Energy 2016, 19, 593-606. [CrossRef]

18. Grunnet, J.D.; Soltani, M.N.; Knudsen, T. Aeolus toolbox for dynamics wind farm model, simulation and control. In Proceedings of the European Wind Energy Conference \& Exhibition (EWEC 2010), Warszawa, Poland, 20-23 April 2010; pp. 3119-3129.

19. Jonkman, J.; Butterfield, S.; Musial, W.; Scott, G. Definition of a 5-MW Reference Wind Turbine for Offshore System Development; Technical Report; Natl. Renew. Energy Lab.: Lakewood, CO, USA, 2009.

20. Mirzaei, M.; Soltani, M.; Poulsen, N.K.; Niemann, H.H. Model based active power control of a wind turbine. In Proceedings of the 2014 American Control Conference, Portland, OR, USA, 4-6 June 2014; pp. 5037-5042. [CrossRef]

21. Göçmen, T.; Laan, P.V.D.; Réthoré, P.E.; Diaz, A.P.; Larsen, G.C.; Ott, S. Wind turbine wake models developed at the technical university of Denmark: A review. Renew. Sustain. Energy Rev. 2016, 60, 752-769. [CrossRef]

22. Peña, A.; Réthoré, P.E.; Rathmann, O. Modeling large offshore wind farms under different atmospheric stability regimes with the Park wake model. Renew. Energy 2014, 70, 164-171. [CrossRef]

23. Wędzik, A.; Siewierski, T.; Szypowski, M. A new method for simultaneous optimizing of wind farm's network layout and cable cross-sections by MILP optimization. Appl. Energy 2016, 182, 525-538. [CrossRef]

24. Rasmus, B.; Knud, R.; Anna-Kathrin, W.; Silke, L. Capacity Densities of European Offshore Wind Farms; Technical Report; Deutsche Wind Guard GmbH: Varel, Germany; 2018.

25. Nienhaus, K.; Hilbert, M. Thermal analysis of a wind turbine generator by applying a model on real measurement data. In Proceedings of the 2012 IEEE International Workshop on Applied Measurements for Power Systems (AMPS) Proceedings, Aachen, Germany, 26-28 September 2012; pp. 92-96. [CrossRef]

26. Qiu, Y.; Zhang, W.; Cao, M.; Feng, Y.; Infield, D. An electro-thermal analysis of a variable-speed doubly-fed induction generator in a wind turbine. Energies 2015, 8, 3386-3402. [CrossRef]

27. Trelea, I.C. The particle swarm optimization algorithm: Convergence analysis and parameter selection. Inf. Process. Lett. 2003, 85, 317-325. [CrossRef]

28. Aziz, N.A.A.; Alias, M.Y.; Mohemmed, A.W.; Aziz, K.A. Particle swarm optimization for constrained and multiobjective problems: A brief review. In Proceedings of the International Conference on Management and Artificial Intelligence, IPEDR, Bali, Indonesia, 1-3 April 2011; Volume 6, pp. 146-150.

29. Hu, X.; Eberhart, R. Solving constrained nonlinear optimization problems with particle swarm optimization. In Proceedings of the Sixth World Multiconference on Systemics, Cybernetics and Informatics, Orlando, FL, USA, 14-18 July 2002.

(C) 2019 by the authors. Licensee MDPI, Basel, Switzerland. This article is an open access article distributed under the terms and conditions of the Creative Commons Attribution (CC BY) license (http://creativecommons.org/licenses/by/4.0/). 